\title{
Temperature influence on the fast pyrolysis of manure samples: char, bio-oil and gases production
}

\author{
Maria Fernandez-Lopez ${ }^{1, *}$, Kostas Anastasakis ${ }^{2}$, Wiebren De Jong ${ }^{2}$, Jose Luis Valverde ${ }^{1}$, \\ and $L u z$ Sanchez-Silva ${ }^{1}$ \\ ${ }^{1}$ Department of Chemical Engineering, University of Castilla-La Mancha. Avda. Camilo José Cela \\ 12, Ciudad Real, 13071 \\ ${ }^{2}$ EDP Sciences, Production Department, 91944 Les Ulis Cedex AFaculty of Mechanical, Maritime \\ and Materials Engineering, Process and Energy Department, Delft University of Technology, \\ Leeghwaterstraat 39, Delft, $2628 \mathrm{CB}$, The Netherlands
}

\begin{abstract}
Fast pyrolysis characterization of three dry manure samples was studied using a pyrolyzer. A heating rate of $600^{\circ} \mathrm{C} / \mathrm{s}$ and a holding time of $10 \mathrm{~s}$ were selected to reproduce industrial conditions. The effect of the peak pyrolysis temperature $\left(600,800\right.$ and $\left.1000^{\circ} \mathrm{C}\right)$ on the pyrolysis product yield and composition was evaluated. Char and bio-oil were gravimetrically quantified. Scanning electron microscopy (SEM) was used to analyse the char structure. $\mathrm{H}_{2}, \mathrm{CH}_{4}, \mathrm{CO}$ and $\mathrm{CO}_{2}$ were measured by means of gas chromatography (GC). A decrease in the char yield and an increase of the gas yield were observed when temperature increased. From $800^{\circ} \mathrm{C}$ on, it was observed that the char yield of samples Dig R and SW were constant, which indicated that the primary devolatilization reactions stopped. This fact was also corroborated by GC analysis. The bio-oil yield slightly increased with temperature, showing a maximum of 20.7 and 27.8 wt.\% for samples Pre and SW, respectively, whereas sample Dig R showed a maximum yield of 16.5 wt. $\%$ at $800^{\circ} \mathrm{C} . \mathrm{CO}_{2}$ and $\mathrm{CO}$ were the main released gases whereas $\mathrm{H}_{2}$ and $\mathrm{CH}_{4}$ production increased with temperature. Finally, an increase of char porosity was observed with temperature.
\end{abstract}

\section{Introduction}

Bioenergy production from renewable energies has been attracted an increasing attention due to the depletion of fossil fuel reserves and the environmental problems derived from their use. Nowadays, the oil consumption rate is about 95 million barrels per day whereas that of natural gas is 9.5 billion cubic meters per day. Therefore, reserves will satisfy 49 years of oil and 70 years of natural gas supply [1]. In this regard, biomass is considered to be one of the most viable energy source [2]. Currently, its contribution to the world annual energy production is about the $10 \%$ [3]. Among the different type of biomass,

* Corresponding author: maria.fernandez@uclm.es 
livestock manure (LSM) is generated from animal fats, carcasses and excrements. The accumulation of LSM has associated some environmental problems such as subterranean and surface water contamination as well as ground and air pollution, odours and greenhouse gases (GHG) and ammonia emissions. In this sense, LSM production accounts for an estimated $14 \%$ and $64 \%$ of the world GHG and $\mathrm{NH}_{3}$ emissions [4]. Therefore, this waste has been traditionally used as fertiliser and landfill. However, these traditional uses have to be changed due to land limitations and the strict regulations [5]. The number of studies about the use of LSM as biomass to produce energy or other added-value products by anaerobic digestion of thermochemical processes has increased in recent years [6-9]. There are many different technologies which have been applied for biomass utilization. Among them, fast pyrolysis is a promising process from which biomass can be converted into liquid, gas and solid products in absence of oxygen and in a short reaction time [10]. The gases mainly consist of small and simple molecules such as carbon dioxide and carbon monoxide, hydrogen and methane whereas light and heavy hydrocarbons are the predominant liquid products. Ash and fixed carbon are the solid products. The distribution of these pyrolytic products depends on the biomass composition and the operating conditions [11]. Solid and gas products are favoured with operating conditions of slow pyrolysis (heating rates up to $100^{\circ} \mathrm{C} / \mathrm{min}$ and high gas residence times) while the liquid yield can be maximized with fast pyrolysis conditions (heating rates from 10 to $200^{\circ} \mathrm{C} / \mathrm{s}$ and gas residence time from 0.5 to $10 \mathrm{~s}$ ) [12-14]. In this sense, Xing et al. (2016) [15] used the analytical pyrolysis-gas chromatography coupled to mass spectrometry (Py-GC/MS) to identify the main compounds generated during the pyrolysis of wood dust and determine the influence of copper and potassium used as catalysts on the pyrolytic products obtained. Ding et al. (2016) [16] studied the production of valuable single ring aromatic compounds from the catalytic pyrolysis of waste tires by Py-GC/MS. They also analysed the catalytic thermal degradation of D-limonene and polybutadiene rubber (BR) to produce these valuable aromatics and proposed a catalytic pyrolysis mechanism based on the product distribution obtained. On the other hand, Gao et al. (2017) [17] investigated the influence of the pyrolytic reaction temperature of rapeseed stalk on the composition and yield of three pyrolytic products to determine the optimum operating temperature for the pyrolysis process. They also performed an economic analysis based on the use of a moving bed reactor for the pyrolytic process.

In this work, the fast pyrolysis of three manure samples was carried out in a pyroprobe pyrolyzer and the three pyrolytic products, namely pyrolytic gas, pyrolytic bio-oil and char, were analysed by gas chromatography (GC) and scanning electron microscope (SEM). The effect of the pyrolysis peak temperature on the product yields, the composition of the gas and the char structure was evaluated. Subsequently, the compositional differences of the products obtained by the three manure samples at different temperatures were presented.

\section{Materials and methods}

\subsection{Biomass samples}

In this work, three dry animal solid waste from the province of Québec (Canada) were selected as biomass feedstock: a swine (SW) manure sample pretreated by a bio-drying process and two dairy manure samples before (Pre) and after (Dig R) an anaerobic digestion process. Pre and Dig R samples were selected to assess the influence of the chemical changes during the biological process on the pyrolytic products obtained from the fast pyrolysis process here studied. These samples were dried in an oven for $5 \mathrm{~h}$, milled and sieved to an average particle size between 150 and $200 \mu \mathrm{m}$. 
On the other hand, the three manure samples were characterized by elemental analysis, thermogravimetric analysis (TGA), bomb calorimetry and atomic emission spectroscopy inductively coupled plasma (ICP-AES). Carbon $(\mathrm{C})$, hydrogen $(\mathrm{H})$, nitrogen $(\mathrm{N})$, oxygen (O) and sulphur (S) were measured in an elemental analyser following the standard UNE-EN 15104:2011 and was expressed as mass percentage of each element in dry basis. Moisture, ash, fixed carbon and volatile matter content were obtained by proximate analysis by TGA and according to ASTM D 3172-73(84) standard. The high heating value (HHV) of the samples was determined using a Parr 1356 bomb calorimeter according to the UNE standard 164001:2005 EX by their combustion under an oxygen atmosphere. Finally, the mineral content was obtained by ICP-AES analysis. Table 1 shows the results of the manure biomass characterization obtained by all the techniques previously commented.

Table 1. Physico-chemical characterization of manure samples (Pre, Dig R and SW).

\begin{tabular}{|c|c|c|c|c|c|c|c|c|c|c|c|c|c|}
\hline & \multicolumn{5}{|c|}{ Ultimate Analysis (wt. \%)* } & \multicolumn{7}{|c|}{ Proximate Analysis (wt. \%) } & \multirow{2}{*}{$\begin{array}{c}\begin{array}{c}\text { Bomb } \\
\text { calorimeter }\end{array} \\
\begin{array}{c}\text { HHV } \\
(\mathbf{M J} / \mathbf{k g})\end{array}\end{array}$} \\
\hline Sample & $\mathbf{C}$ & $\mathbf{H}$ & $\mathbf{N}$ & $\mathrm{s}$ & O** & \multicolumn{2}{|c|}{ Moisture } & \multicolumn{2}{|c|}{ Ash } & \multicolumn{2}{|c|}{$\begin{array}{l}\text { Volatile } \\
\text { matter }\end{array}$} & $\begin{array}{c}\text { Fixed } \\
\text { carbon** }\end{array}$ & \\
\hline Pre & 51.43 & 6.72 & 1.7 & 0. & 39.59 & \multicolumn{2}{|c|}{3.45} & \multicolumn{2}{|c|}{20.78} & \multicolumn{2}{|c|}{64.09} & 11.68 & 18.4 \\
\hline Dig R & 51.50 & 6.48 & $1.2^{7}$ & 0. & 40.20 & \multicolumn{2}{|c|}{2.90} & \multicolumn{2}{|c|}{28.09} & \multicolumn{2}{|c|}{56.68} & 12.33 & 16.9 \\
\hline SW & 45.00 & 6.40 & 1.90 & 0. & 45.98 & \multicolumn{2}{|c|}{4.41} & 9.7 & \multicolumn{3}{|c|}{66.30} & 19.57 & 16.1 \\
\hline \multicolumn{14}{|c|}{ Mineral content and $\mathrm{Cl}^{-}, \mathrm{CN}^{-}$content (ppm) } \\
\hline & Al & $\mathbf{C a}$ & $\mathbf{C r}$ & $\mathbf{C u}$ & $\mathbf{F e}$ & Mg & \multicolumn{2}{|c|}{$\mathrm{Na}$} & F & P & $\mathbf{S i}$ & \multicolumn{2}{|c|}{$\mathrm{Cl}^{-}$} \\
\hline Pre & 516 & 16997 & 73 & - & 3800 & 6426 & \multicolumn{2}{|c|}{37445} & 162 & 207 & 537 & \multicolumn{2}{|c|}{42866} \\
\hline Dig R & 238 & 22214 & 127 & - & 3589 & 8720 & \multicolumn{2}{|c|}{6392} & 210 & 993 & 525 & \multicolumn{2}{|c|}{20325} \\
\hline SW & - & 10070 & - & 142 & 4626 & 4465 & \multicolumn{2}{|c|}{2356} & 175 & 568 & 278 & \multicolumn{2}{|c|}{18779} \\
\hline
\end{tabular}

*daf: dry ash free; **obtained by difference

\subsection{Pyrolysis experiments}

Fast pyrolysis experiments of manure samples were carried out in a commercial pyroprobe pyrolyzer (CDS5200) using nitrogen as the carrier gas with a constant flow rate of $17 \mathrm{~mL} / \mathrm{min} .30 \mathrm{mg}$ of sample was introduced in a quartz tube in each experiment. Raw material was placed in the middle with quartz wool on both sides. Then, the quartz tube with the sample was located into the pyroprobe and heated up to the pyrolysis peak temperature at $600^{\circ} \mathrm{C} / \mathrm{s}$. Finally, the temperature was kept for $10 \mathrm{~s}$ to reproduce industrial conditions [18]. Three pyrolysis peak temperatures for each manure biomass sample were studied: $600^{\circ} \mathrm{C}, 800^{\circ} \mathrm{C}$ and $1000^{\circ} \mathrm{C}$. Each experiment was repeated at least twice to ensure data reproducibility.

The gas products evolved passed through a trap where the condensable gases were captured at $50^{\circ} \mathrm{C}$. Subsequently, permanent or non-condensable gases were collected in a syringe at room temperature and then analysed by GC using a micro-gas chromatograph (Varian CP-4900). $\mathrm{CO}_{2}, \mathrm{CO}, \mathrm{CH}_{4}$ and $\mathrm{H}_{2}$ were the main gases produced and analysed. Finally, biomass manure samples and pyrolytic chars obtained after fast pyrolysis were analysed by SEM.

Char and bio-oil were gravimetrically quantified and the pyrolytic product yields were calculated as follows: 
Char yield $(\%)=(m g$ of residue after pyrolysis $/ m g$ of initial sample weight $) * 100$

Bio-oil yield $(\%)=($ mg of bio-oil/mg of initial sample weight $) * 100$

On the other hand, the gas yield of each gas $\left(\mathrm{CO}_{2}, \mathrm{CO}, \mathrm{CH}_{4}\right.$ and $\left.\mathrm{H}_{2}\right)$ was calculated using the results from $\mathrm{GC}$ and the ideal gas law (considering $293 \mathrm{~K}$ and 1 bar).

Individual Gas yield $(\%)=(m g$ of gas/mg of initial sample weight $) * 100$

Therefore, the gas yield was calculated as:

Gas yield $(\%)=\left(\Sigma\left(\mathrm{CO}_{2}, \mathrm{CO}, \mathrm{CH}_{4}\right.\right.$ and $\left.\mathrm{H}_{2} \mathrm{mg}\right) / \mathrm{mg}$ of initial sample weight $) * 100$

\section{Results}

The influence of three different peak pyrolysis temperatures $\left(600,800\right.$ and $\left.1000^{\circ} \mathrm{C}\right)$ on the product yields and compositions during fast pyrolysis $\left(600^{\circ} \mathrm{C} / \mathrm{s}\right)$ in a pyroprobe pyrolyzer was studied for the three manure samples considered in this study. Devolatilization is the main process which takes place during fast pyrolysis, leading to three pyrolytic products, namely char (solid residue after pyrolysis), bio-oil (condensable gases) and gaseous compounds. These products were individually measured and analysed. Fig. 1 shows the product yield results with the standard deviation for samples Pre (A), Dig R (B) and SW (C) in a dry basis (d.b.).

Generally, the devolatilization product yields followed the same trend for the three samples studied. A decrease of char yield and an increase of gas and bio-oil yields were obtained with the increase of the peak pyrolysis temperature. As it can be observed in Fig. 1, a decrease in the char yield from 52 to $31,60.5$ to 45.2 and 35 to 28 wt.\% and an increase of gas yield from 7.7 to $16.2,7.8$ to 14.4 and 10.3 to $17.3 \mathrm{wt} \% \%$ were observed when the peak pyrolysis temperature increased from 600 to $1000^{\circ} \mathrm{C}$ for samples Pre, Dig R and SW, respectively. Char yield of samples Dig R and SW were constant (46 and $28 \mathrm{wt} . \%$, respectively) from $800^{\circ} \mathrm{C}$ which indicated that the primary devolatilization reactions stopped. This fact was also corroborated for both samples with the evolved gas analysis, where a constant $\mathrm{CO}_{2}$ production was also observed. In agreement with the proximate analysis (Table 1), sample Dig $\mathrm{R}$ at $1000^{\circ} \mathrm{C}$ appeared to be the highest value of final char residue and ash and FC content.

On the other hand, the bio-oil yield slightly increased with temperature except for sample Dig R. The maximum bio-oil yields were 20.7 and $27.8 \mathrm{wt} . \%$ at $1000^{\circ} \mathrm{C}$ for samples Pre and SW, respectively and 16.5 wt. $\%$ at $800^{\circ} \mathrm{C}$ for sample Dig R. 

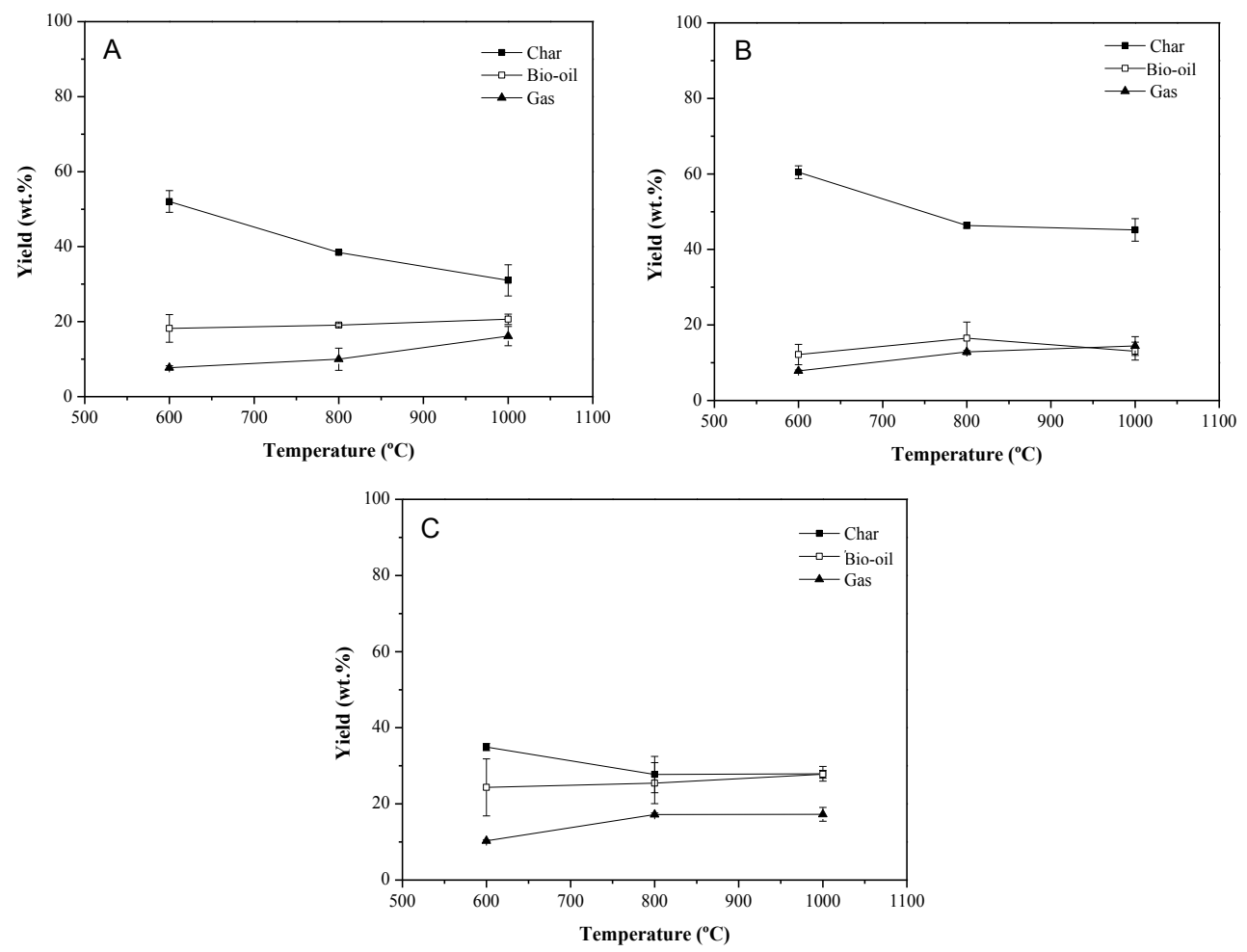

Fig. 1. Char, bio-oil and gas yield during fast pyrolysis of samples Pre (A), Dig R (B) and SW (C).

Concerning the gas fraction, a micro-gas chromatographer was used to analyse and quantify the main gaseous species evolved during fast pyrolysis. Fig. 2 shows the mass yield (d.b.) of the main gases evolved during fast pyrolysis of samples Pre (A), Dig R (B) and SW (C) as a function of the peak pyrolysis temperature.

As it can be seen in Fig. 2, there was an increase in the yield of all species with the increase of the temperature, which indicated that the formation reactions of these gaseous species were thermally favoured. Gases evolved can be either the products of primary decomposition reactions by the bond breaking of cellulose, hemicellulose or lignin, or those coming from secondary cracking ones [18].

$\mathrm{CO}_{2}$ and $\mathrm{CO}$ were the main released gases for all the samples in the range of temperatures studied [19]. $\mathrm{H}_{2}$ and $\mathrm{CH}_{4}$ production increased when the temperature also did. In Fig. 2, the increase of $\mathrm{CO}_{2}$ production in all the range of temperatures for sample Pre could indicated that primary devolatilization reactions did not stop at high temperatures whereas for samples Dig R and SW the production of $\mathrm{CO}_{2}$ was stable from $800^{\circ} \mathrm{C}$ on as it was previously mentioned.

Fig. 3 shows the SEM images of raw sample Pre (A) and the char remained after fast pyrolysis at $600^{\circ} \mathrm{C}(\mathrm{B}), 800^{\circ} \mathrm{C}$ (C) and $1000^{\circ} \mathrm{C}$ (D). According to these SEM images, the char morphology changed with the pyrolysis peak temperature [19]. Overall, it was observed that the porosity increased as the pyrolysis temperature increased due to the release of volatiles compounds during thermochemical degradation [20,21]. The higher the pyrolysis temperature, the lower the pore sizes of the char [19]. The pore network observed for chars suggest their potential use as soil amendment. The porosity can play an important role for helping as a storage of water in soil, serving as habitat for a variety of 
microorganism, and help in the root movement in soils [20]. On the other hand, these chars could be also be used depending on the pore size as gas adsorbent.
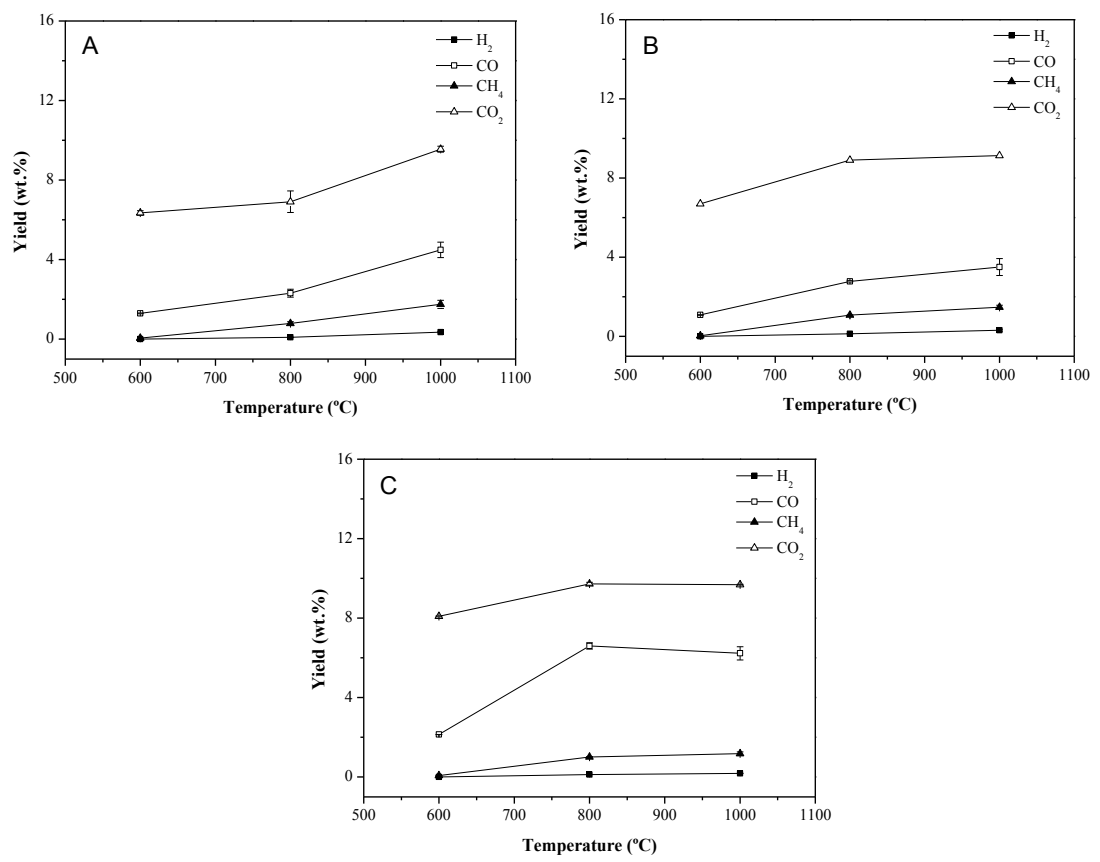

Fig. 2. $\mathrm{H}_{2}, \mathrm{CH}_{4}, \mathrm{CO}$ and $\mathrm{CO}_{2}$ mass yield obtained during fast pyrolysis of sample Pre.
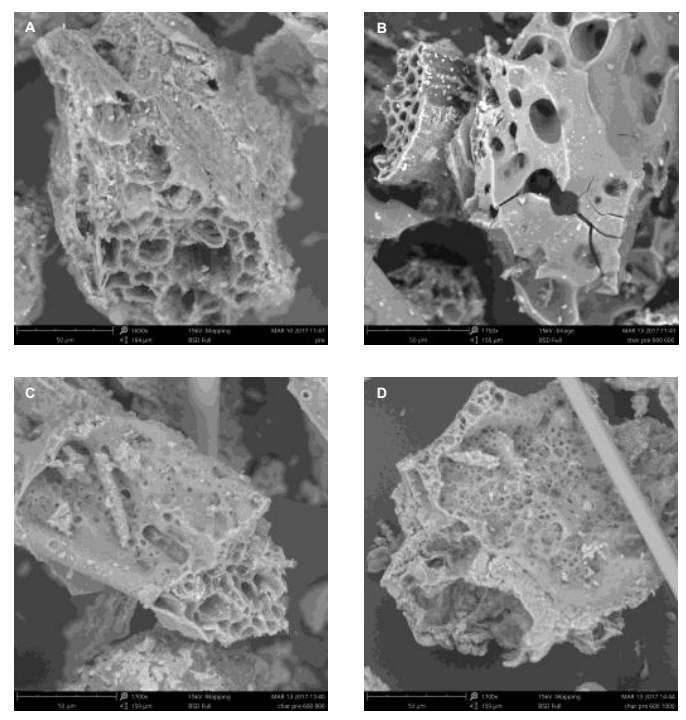

Fig. 3. SEM images of sample Pre (A) and chars obtained from this sample during fast pyrolysis at $600^{\circ} \mathrm{C}(\mathrm{B}), 800^{\circ} \mathrm{C}(\mathrm{C})$ and $1000^{\circ} \mathrm{C}(\mathrm{D})$. 
Authors acknowledge the financial support from the Regional Government of Castilla-La Mancha (Project PEII-2014-007-P) and also from the University of Castilla-La Mancha of Spain (UCLM grant). The authors also thank to the Centre National en Électrochimie et Technologies Environnementales (CNETE) of Canada for its in-kind contribution.

\section{References}

1. BP (2016)

2. F. Pierobon, M. Zanetti, S. Grigolato, A. Sgarbossa, T. Anfodillo, R. Cavalli, Appl. Energ. 150, 185-195 (2015)

3. WEC

4. L. Loyon, C.H. Burton, T. Misselbrook, J. Webb, F.X. Philippe, M. Aguilar, M. Doreau, M. Hassouna, T. Veldkamp, J.Y. Dourmad, A. Bonmati, E. Grimm, S.G. Sommer, J. Environ. Manage. 166, 1-11 (2016)

5. J.-P. Cao, X. Huang, X.-Y. Zhao, X.-Y. Wei, T. Takarada, Fuel 140, 477-483 (2015)

6. U. Ekpo, A.B. Ross, M.A. Camargo-Valero, P.T. Williams, Bioresour. Technol. 200, 951-960 (2016)

7. N. Ruiz-Gómez, V. Quispe, J. Ábrego, M. Atienza-Martínez, M.B. Murillo, G. Gea, Waste Manage. 59, 211-221 (2017)

8. M.S. Hussein, K.G. Burra, R.S. Amano, A.K. Gupta, Fuel 189, 428-435 (2017)

9. K.G. Burra, M.S. Hussein, R.S. Amano, A.K. Gupta, Appl. Energ. 181, 408-415 (2016)

10. A.V. Bridgwater, Biomass Bioenergy 38, 68-94 (2012)

11. J. Akhtar, N. Saidina Amin, Renew. Sustain. Energy. Rev. 16, 5101-5109 (2012)

12. L. Chen, X. Zhang, L. Sun, H. Xu, H. Si, N. Mei, Energy Fuels 30, 10222-10227 (2016)

13. W.N.R.W. Isahak, M.W.M. Hisham, M.A. Yarmo, T.Y. Yun Hin, Renew. Sustain. Energy. Rev. 16, 5910-5923 (2012)

14. M.I. Jahirul, M.G. Rasul, A.A. Chowdhury, N. Ashwath, Energies 5, 4952-5001 (2012)

15. S. Xing, H. Yuan, Huhetaoli, Y. Qi, P. Lv, Z. Yuan, Y. Chen, Energy 114, 634-646 (2016)

16. K. Ding, Z. Zhong, B. Zhang, J. Wang, A. Min, R. Ruan, J. Anal. Appl. Pyrolysis 122, 55-63 (2016)

17. Y. Gao, X. Wang, Y. Chen, P. Li, H. Liu, H. Chen, Energy 122, 482-491 (2017)

18. K. Anastasakis, I. Kitsiou, W. de Jong, Fuel Process. Technol. 142, 157-166 (2016)

19. A.M. Widiyannita, R.B. Cahyono, A. Budiman, Sutijan, T. Akiyama, AIP Conference Proceedings 1755, (2016)

20. D. Rehrah, R.R. Bansode, O. Hassan, M. Ahmedna, J. Anal. Appl. Pyrolysis 118, 42-53 (2016)

21. N. Claoston, A. Samsuri, M.A. Husni, M.M. Amran, Waste Manage. Res. 32, 331-339 (2014) 